1933

\title{
Chronic epidemic encephalitis
}

Percy A. Reitz

University of Nebraska Medical Center

This manuscript is historical in nature and may not reflect current medical research and practice. Search PubMed for current research.

Follow this and additional works at: https://digitalcommons.unmc.edu/mdtheses

\section{Recommended Citation}

Reitz, Percy A., "Chronic epidemic encephalitis" (1933). MD Theses. 285.

https://digitalcommons.unmc.edu/mdtheses/285

This Thesis is brought to you for free and open access by the Special Collections at DigitalCommons@UNMC. It has been accepted for inclusion in MD Theses by an authorized administrator of DigitalCommons@UNMC. For more information, please contact digitalcommons@unmc.edu. 
CHRONIC EPIDEMIC ENCEPHALITIS

SENIOR THESIS

PERCY A. REITZ

MARCH 28,1933 


\section{PREFACE}

The purpose of this paper is not to offer anything new on this devastating disease, which has been so thoroughly discussed in all the journals of neurology and psychiatry for the past thirteen years, but it is merely to present the problem as it confronts the medical profession, and to give a brief resume of literature and clinical findings as are commonly met. 
Up until 1917 medical science had been confronted with only two chronic inflammatory diseases of the cerebrospinal system, namely cerebrospinal syphilis and multiple sclerosis. The first being infectious and the second probably so. Since 1917 the world has been confronted with another inflammatory disease of the cerebrospinal system which is so protean and devastating in its ravages on humanity that it has far surpassed the other two. Since that time, when practically nothing was in the medical literature, it now carries large amounts, and if all collected together would make quite a considerable library. Time would not permit, and since a large amount is relatively repetition I have only reviewed such articles which seemed to have definite bearing particularly on the chronic phase of this scourge. In this paper I will attempt to review the subject somewhat with special emphasis on the post-encephalitis, or better, chronic epidemic encephalitis phase.

There has been, and still is, some discussion among workers and Writers as to whether this disease does become chronic or whether the symptoms shown are only a reaction to the damage rendered by the acute infection which is the opinion held by. Iroy Mckenzie. Stern and Mourge (49) have suggested that the causative virus may produce metabolic changes, the effect of which may produce leisons in the basal ganglion. There may be some evidence to back this theory since it has not been thoroughly worked out as yet. 
However, post-mortem evidence is regarded as most evident. Hohman (39) states that a striking feature was the universal finding of persistent signs of subacute inflammation present. Freeman (30) noticed presence of fat scavenger cells, collections of $1 \mathrm{ym}-$ phocytes in the sheath of blood vessels and compared this with general paresis which is beyond doubt chronic. Greenfield (33) states that while perivascular infiltration was evidence of subacute inflarnation, the most prominent sign was neuronal decay. Von Economo (30) spoke of it as being a progressive state as early as 1919. Nonne (30) found there might be an interval of three to four years after the acute attack before the appearance of sequelae, so called.

Perkins (57) speaks of it as chronic and sequelae. Levy, HaII, Stiefler and Winner, all of foreign countries, call it chronic, as is stated by Freeman (30). Freeman (30) also says, "What acute disease can give such striking sequelae." Hunter (40) in writing says, "It may, Iike syphilis, remain active for years within the nervous system, causing recurrent outbursts slow inflammatory leisons or a gradual disappearance of nerve cells in the basal ganglion and increasing disability of the patient. It is thus more logical to speak of chronic epidemic encephalitis rather than sequelae."

So, in this paper, I will speak of it as chronic epidemic encephalitis. 
In reviewing the historical aspect of the disease, we might first look to the history of the epidemic of 1918 and 1919.

The disease first made its appearance, according to Von Economo (71) by a single case observed by Urechia in Roumania in 1915. The second was observed by Cruchet (5) in the autumn of that same year on the Western Front in a French soldier. These cases apparently being sporadic; however, the first signs of it becoming epidemic appeared with it as it appeared in Northern Austria and Vienna in 1916. From here it apparently spread throughout the entire world, appearing in France and England in the winter of 1918, and in this country during the winter of 1918 and 1919.

Various writers have delved into the depths of the medical literature in order to discover whether it was known to the ancients. Jonathan Wright (71) in reviewing the works of Hippocrates states, "It is evident, however, to us that neither Hippocrates nor his French translator was familiar with the epidemic which has confronted us.

Celsus in his writings only refers to lethargy incidently in stupor of epileptics in which he thinks it foolish to arouse them because he thinks lethargy is not cured in that way. Still following Wright's historical review, Pilny only mentions lethargy in connection with poisoning from the bite of a viper.

Rufus' works have passed through the hands of the Arabs and now are in such a jumble that nothing can be made from them. He does, however, speak of the leaden countenance and slow movements. 
The rest cannot be deciohered and we are still at a loss to state whether he knew the disease or not. He probably lived about 98 117 A. D.

According to Riley (60) Galen recognized the disease, but Wright in discussing Galen states "For Galen lethargy arose from phlegm, as it did for Hippocrates." If the disease was present in the Roman Empire as a new disease, he failed to recognize it, and his works fail to describe it."

Aretaeus, shortly after Galen, according to Wright (71) has shown that he recognized-the disease as did Calius, then goes on to state that this is conjecture. Riley seems to think that it was recognized by him.

Paulus Aegineta and Trallianus, as Wright seems to think, were apparently acquainted with the disease.

Wright points that the first man to discuss and describe the disease was Caelius Aurelianus, who was a Numidian and a contemporary of Galen, in his books "De Morbis Acutis" the first chapter "De Lethargo," he gives a description of lethargy, and how it is distinguished from those similarly affected. What happens to those who fall into lethargy? How lethargy is to be diagnosed from other maladies? How the lethargies differ and how they are cured?

Then going into the Dark Ages, nothing seems to show any reference to it. During the Renaissance it was suggested by Desousa in Lisbon in Mendorra of Mordorillo in 1921. 
It probably was "The Pestilence Soporense" described by Amatus which occurred in Italy in 1561. In 1695 Albrect (5) of Germany described a disease which he called "Lethargy with Ocular Symptons" which perhaps may have been identical. "Schlafkraukheit", or Somnolence wth Opthalmoplegia, described by Camerartus of Tubingen in 1718 is perhaps a reference to the scourge. In 1768 Lequeca de la Cloture described "Coma Somnolence" and Ocranann, who in 1835 mentioned epidemics of "Catarrhal Fever" with Saporiosite" or somnolence. In 1875, Gayet or Lyons described a disease characterized by ophthalmoplegia of subacute onset, accompanied by apathy and somnolence, and that it had occurred as an epidemic in Lyons in 1800 and in milon in 1802. The last description of such an outbreak was given by Louquet under the name of "Nona" in Northern Italy, spreading to Hungary, Germany, France, and Italy itself, but not to America. Somnolence seemed to be the prominent feature and cranial nerve palsies were also prominent. This gives the summary of as much of the historical past as seems to be found in recent literature and upon which most of the writers agree to be the correct past of this malady. For this work on the historical aspect of this disease credit must be given to wright's series of articles. (71) 


$$
-6-
$$

Chronic epidemic encephalitis might be defined as a progressive disease of the central nervous system of unknown etiology, with definite pathological findings in the brain stem and basal ganglia characterized symptomatically by a very wide and definite chain of neurological and psychiatrical symptoms, following an acute attack of epidemic encephalitis, which may have been quite severe or so mild it was not noticed by the patient.

The causative agent of this unapproachable disease still remains an unsolved mystery. There has been considerable work done in animal experimentation and nothing very definitely concluded.

When the first few cases were noticed in Austria it was thought to have been due to poisoning from the eating of spoiled sausage. In England it was thought to result from food poisoning from botulinus toxin. These ideas soon fell by the way side.

Organisms have been isolated by various workers such as Von Wiesner working with Von Economo, Roseneau of Hayo Clinic, Evens and Freeman, House and many others, but on further experimentation the presence of a definite visible organism is not yet proven to the workers at large.

In the Hathewson Commission, Stern (48) is quoted as believing epidemic encephalitis to be a definite clinical entity. He divides the causative agent theories, into three classes which he says have all been claimed as etiological factors and which serious objections have been raised against all of them. 
They are (1) a particularly neurotropic form of streptococcus or streptococcus toxin, (2) the herpetiform encephalitis virus and (3) the chronic form of encephalitis of toxic origin from an apparent non-specific virus.

At first it was though that the causative agent of influenza and epidemic encephalitis were symbiotic and Peter Bossoe (5) in discussing this in 1919 states, "It is striking that the only epidemics appearing in the past have been with influenza epidemics".

Flexner (28) has shown that this is a coincidence and that the encephalitis epidemic started in 1916, while the influenza started in 1917 and the second outbreak of epidemic encephalitis, which came in 1924, was not accompanied with influenza.

T. R. Hill (15) in discussing Perdrau's work on virus, states that he divides it into three types of infection, the first in which there is immunity developed and the infective agent is destroyed. The second class in which there is partial immunity and it becomes chronic and the third class where there is no immunity and the disease goes to a rapid termination. Perdrau's theory of the herpes virus is that herpes febralis is caused by a living virus which is found to live on the mucus membranes and may be pathogenic enough for man to cause herpes zooster by a local invasion of the central nervous system. That there is a different herpes virus very pathogenic for man and the causative agent of epidemic encephalitis. 
Doerr in 1924 (15) summed up the arguments for and against herpes virus. His arguments for herpes infection are:-

1. Virus has been isolated from the cerebrospinal fluid and brain in cases of epidemic encephalitis which acts as herpes febralis virus in rabbits.

2. Herpes virus in animals causes a clinical picture like that seen in epidemic encephalitis in man.

3. Herpes virus seems to travel from its portal of entry along nerves to the central nervous system.

4. Epidemic encephalitis is an infectious disease and no other causative agent has been found.

His arguments against herpes infection are:-

1. Herpes febralis is common while epidemic encephalitis is rare.

2. The occurrence of epidemic encephalitis is not accompanied by an increase of incidence or severity of herpes febralis.

3. A conclusive example of epidemic encephalitis resulting from herpes labialis or cornea is not known in man.

4. Epidemic encephalitis is not produced in man by intrathecal injections of herpes virus.

5. Herpes is rare in epidemic encephalitis, but common in meningitis and pneumonia.

6. Herpes has been found only in a small number of cases in which it has been sought for. 
In looking over the Mathewson Report, we find a multitude of references to literature of experimental work which has been carried out in foreign countries as well as this country, none of which is conclusive evidence as to cause, but they all seem, or the marjority to be of the opinion that the disease is a clinical entity.

Levaditi (49) concludes that the neurotropic herpes virus isolated by himself and other workers, is the most probable etiological agent of epidemic encephalitis, but does not claim that this has been proven.

Von Economo (49) suggests that perhaps only some fundamentally new discovery such as the investigation of bacteriophage will solve the problems of epidemic encephalitis. Zinsser (49), in working with virus on monkeys, concludes that while his experiments may give valuable evidence, they do not give conclusive proof.

Weschler (67) in his opening statement in discussing the cause says "The cause of epidemic encephalitis is not known." Likevise, the second report of the Matheson Comnission (49) in their final statement conclude, "Again it is necessary to conclude that the question of the etiology of epidemic encephalitis is still unanswered."

It might be expected from the great variety and the manifestations of the different symptoms, that there would be considerable destruction of nervous tissue. This supposition is, however, not verified by post-mortem findings.

The most marked feature seen in the acute case is congestion. 
The meningeal vessels, particularly over the brain system, are engorged with blood, and on the cut surface of the brain are seen many tiny vessels, both in the gray and white matter. As a rule this is more marked in the brain stem than other parts of the brain, but often minute punctate hemorrhages are seen profusely scattered in the gray and white matter of the cerebrum, cerebellum, pons and medulla equally without any particular localization. Boyd (16) describes a case in which the cerebral hemispheres were of a salmon color and states in some cases that the hemorrhages were so great it could not be distinguished from appoplexy without the aid of a microscope.

Boyd (16) describes the microscopic leisons of the acute stage under two heads--the interstitual and the parenchymatous, The former he states is a very common finding and he found it in one hundred per cent of his cases. The hemorrhages are usually very small and are confined to the perivascular spaces which surround the small cerebra vessels.

The most familiar leison of the chronic stage is the "collar" or "sleeve", as some have described it, of cells which surround the small vessels and are often confined to the Virchow-Robin spaces in the advantitia, in other cases there is an overflow into the perivascular space of His. This "collar" is not specific of epidemic encephalitis as it is seen in cases of general paresis, tuberculosis, meningitis, rabies, chorea, sleeping sickness, and poliomyelitis. 
The cells forming this collar are nearly all mononuclear. Occasionally a polymorphonuclear cell is seen, and they have been described by Boyd (15) Tilney and Howe and Fey (65).

Amyloid bodies have frequently been described in the brain stern, especially in the walls of the aqueduct and floor of the fourth ventricle. These seem to hyaline in appearance, spherical in outline, and present concentric markings. Calcareous deposits have also been described in this same region.

The parenchymatous changes consist of degeneration. Von Economo (66) insists this is the most prominent and primary feature. These changes are seen occasionally in the cortex, but are most cormonly seen in the cranial nerve nuclei; especially of the third, sixth, seventh, and eighth nerves. Boyd (15) states that the third was most often affected, being found such in seventy-five per cent of his cases of his first series. In taking it as a whole leions of this kind have been found in the whole aqueduct region, the substantia nigra, (especially prominent in Parkinsonisin) corpus striatum, optic thalmus, hypothalmus, red nucleus, basal ganglion and the rest of the mid-brain region.

The greater majority of the lelsons are in the gray rather than the white matter. While leisons have been described in the cortex of the cerebellum and cerebrum, Boyd (15) failed to find any in the cerebellum. Flexner has been quoted as having found leisons in the cervical cord. Boyd (15) in discussing this states that leisons of the cervical cord in his studies could not be spoken about with certainly. 
Pathologically speaking we may say that this is essentially a disease of the midbrain.

There is no known disease of the central or peripheral nervous system which is capable of producing such an all-inclusive syraptomatology as epidemic encephalitis. Formerly syphilis was given as a disease which was capable of producing protean manefestations of the nervous system unequaled by any disease, but with the advent of epidemic encephalitis, syphilis has been pushed back beyond the horizon and its place is now occupied with the topic of our discussion. Epidemic encephalitis has not only taken its place, but has made it only a mere insignificant thing.

The symptoms are in no way significant of the final outcome. The symptoms may be of catarrhal character or entirely lacking, or so insignificant that the patient does not notice them, and later he develops, to his surprise, the symptoms of chronic epidemic encephalitis.

In an article by Flexner (28) in 1920, he gives a rather complete symptomology which he had noticed in his cases, and which he had collected from the literature. The onset, he says, is usually one of an upper respiratory infection such as chill, lassitude, general malaise, headache, general pains, nausea and anorexia, with temperature from one hundred and one degrees to one hundred and two degrees usually, but it may have gone as high as one hundred and four degrees. 
As the symptoms develop, there axises lethargy, vertigo, tinnitis, muscular weakness, diplopia, blurred vision, photophobia, tremors, twitchings, ataxia, delerium, irritability, mental depression, difficulty in talking and swallowing, stiff neck, spasticity of muscles sweating and hiccough. The earliest symptoms, he found, were usually the eye symptoms and cranial nerve palsies. Lethargy was present in eighty per cent of the cases, while the other symptoms varied in their appearance.

Tilney and Howe (65) in their analysis of the symptoms 1 ist eight main groups, the onset, lethargy, cranial nerve palsies, temperature, tremors, asthenia, restlessness and catalepsy.

Blackstone (11) in giving the thirty-nine cases of A. W. Young of Chronic Parkinsonion gives the symptoms of the original onset as, in twenty-six cases there was somnolence, diplopia in nineteen cases, delerium in eleven, restlessness in six, headache in five and giddiness in two.

Weschler (67) in his opening statement of the symptoms says, "Ho meticulous enumeration of signs and symptoms or orderly grouping into multitudinous types can give an adequate picture of the symptomology of epidemic encephalitis."

Boyd (15), in discussing the cases of the first epidemic, seemed to place diplopia, lethargy, or a coma, which was different from other comas in that the patient could be aroused and made to answer questions but would fall back into his peculiar coma the minute he was Ieft alone, other cranial nerve involvements, especially facial palsies and some neck rigidity. 
Along with these symptons there was usually found no change in deep reflexes or superficial reflexes. There may have been bulbar signs such as rapid pulse, high fever and rapid respixation, which usually ended fataliy. Often the disease would begin with a certain fury but the acute stage would soon be cut short by the patient developing a Parkinson syndrome. Retention of urine has also been reported. He then goes on to discuss the subsequent epidemics in which seemed to show a somewhat different symptomatology in that there was often found insomia rather than lethargy, or there may have been a change of the sleep curve in that the patient would sleep all day and lie awake all night. The mental disorders were found more frequently such as delerium, hallucinations, and delusions. The deep reflexes.were more active while abdominal reflexes were absent. The onset was often very sudden. A patient might go to bed at night feeling quite well, or perhaps not "just himself," only to awake the following morning with a full fledged Parkinson syndrome. Athetoid and choreiform movements were more comnon, and tics often developed.

The laboratory findings in these cases apparently were not at all characteristic, but significant. Dunn and Heagey (22) in fifteen cases found a slight leucocytosis, ten thousand six hundred with seventy per cent polymorphonucleas, leucocytes, while the hemoglobin and erythrocyte count were normal. 
Neal (5I) in a review of forty cases states that she found a slight leucocytosis, but other blood findings apparently normal, as the usual findings were.

In the spinal fluid findings, somewhat similar results were obtained. Dunn and Heagley (22) reported pressure of seven to fifteen millimeters of mercury, clear with an average cell count of nine. Neal (5l) in forty cases found slight to moderate increase of cell count in thirty-three cases, absent in seven. Increased protein in all but one case, gold curves in three cases but not characteristic, spinal fluid usually under moderate pressure, and clear. Flexner (28) states that the fluid was under pressure, clear cells usually ten to twenty per cubic millimeter, rarely above one hundred. Steen and steen (45) in a series of sixty-one cases found in $47.5 \%$ of the cases an increase of pressure, $18.1 \%$ showed increase of globulin, $15 \%$ showed increased cell count, sugar was normal throughout, in six cases clinically severe there were no abnormal findings. Riley (60) states that seventy to seventy-five per cent of the cases show some deviation, pressure, he says, varies from fifteen to twenty-three millimeters of mercury cells from ten to twenty-five per cent per cubix millimeter, colloidal gold almost any reaction, sugar normal and practically always clear, which seems to show that there were some serological findings, but like the other signs and symptoms, not always present, and to the fluid findings are however found in the acute stage more often than in the Chronic stage. 
The urine seems to show nothing of any value in regard to this disease, which was the result found by most of the workers.

The symptoms of the acute attack play very little part in the prognosis or final result of the disease. The late manifestations were at first thought to be the result of the "scars" caused by the acute infection. Years, months or days following the acute stage they may have an acute exacerbation and the latent signs appear or they may appear without any noticable exacerbation. The patient may notice some stiffness of his muscels, tendency to fatigue, slowness of motion, inability to think and act quickly, appearance of a tremor, loss of facial expression and a drooling of saliva. These symptoms once established fall to recede. They may remain stationary, or increase so that the patient is unable to swallow or feed himself and is confined to bed where he dies of inanation or some incurrent infection.

Grossman (34) gives a report of ninety-two cases which he examined who had had an acute attack one to three years previously. In a previous report he stated that twenty per cent who got the acute attack died, ten per cent who got over the acute attack develop a progressive state, the remainder will make a good functional recovery in six to twelve months following. But, in his later report of the ninety cases, these percentages have changed somewhat. 
of the ninety-two, ten had recovered with no complaints, fourteen others who had recovered sufficiently so that they could go to work but they all showed some signs of residual infection, and all but one complained of some psychic disturbances such as insomnia, irritability, depression, or headache and fear. Forty-two showed the Parkinson syndrome, and the others showed various other manifestations.

He then goes on to list the symptoms as found in the whole ninety-two cases. In the cranial nerve disturbances he found facial muscles involved, giving rise to the masked face; recti muscles of the eyes involved, giving rise to ptosis, oculogyric crises, tremors of the lids; facial tics; tremors of the tongue loss of accomodation, or the Argyl1-Robertson pupil or reversed Argyl1-Robertson pupil, and irregularites of outline. Under nervous disturbances he lists, disturbances of the attitude of the head, extremities and trunk; muscular rigidity; upper arm flexed at the elbow and wrist with the fingers and thumb adducted; atrophy of the thenar and interossi muscles; disturbance of gait, giving rise to retropulsion, propulsion lateropulsion and hemiphlegic; disturbances of speech, being slow and monotonous and hard to understand; ataxic tremors; intention tremors; lack of associated movements in walking such as swinging of the arms; muscle tonus increased, and the cogwheel phenomen. The superficial reflexes were disturbed being absent, present and hyperactive. Deep reflexes also show some alteration such as hyperactive on one or both sides or no alteration whatever, Babinski varied from absent to present and the ankle jerk varied in the same proportions. 
Disturbances found in the autonomic systern were hands and feet cold, drooling of saliva, flushing of areas, sweaty oily facies, difficulty of urination, alterations of sexual desire, widening of the palprebal fissure and exophthalmus. The psychic disturbances varied considerably, he found cases showed visual hallucinations, psychoneurosis, fear and compulsion neurosis, anxiety states, hysterical exaggeration of symptoms were frequently found, insomnia, drowsiness, marked depression, loss of interest, failing of memory, irritableness, hypomania, lack of concentration and stealing. Other symptoms which he found but did not classify were difficulty of breathing, suicidal tendencles, choreiform and choreioathetoid movements, tic-like tossings of the head, cases simulating myasthenia gravis and Huntington's chorea. Physically the patients thought they were getting worse but signs showed only a slight progression. With such a multitude of symptoms one would hardly wonder at the gravity of this disease.

Henri Rogers (61) has classified some of the rather rare symptom complexes and called them spasms of function, which will be discussed in brief.

The ooulogyric crises, which is a term applied to the syndrome in which paroxysmal spasmodic conjugate diviation of the eyeballs occur, elther upward, downward or lateralward. The eyes become fixed in one plane, frequently showing nystagmoid movements and fluttering or closure of the eyelid which might last several minutes to days. It was first described by Albrecht in $1695(10)$. 
The attacks seem to be precipitated by emotion, fatigue, sounds and odors. In one of the cases, Case I, which I have submitted, is such a case in this girl the attacks were percipitated most frequently When she was bathed and also during her menstruation. Another such case is one that I saw in the dispensory. Hex attacks, she stated, came only when she had forgotten to take her medicine (tincture of stromonium). In the former, she would go into tantrums at this time and attack any one near her, regardless of who they were, while ordinarily she was a very peaceable girl. Suicidal tendencies have often been described occurring during these attacks.

Jellife (44) likens it to a hysterical affair and bases it on a compulsion neurosis. Bennet and Patton (8) state that pathological explanations are hypothetical because no necropsy has been reported. Some think the striopallidal system, others the anterior part of the corpora quadrigerina is the seat of pathology.

Other spasms of function as described by Rogers are facial cervical and thorasic. In the facial he describes palprebal occlusion or orbicularis spasm, perpetual grimaces, spasms of mastication, spasms of the tongue, lips, of degulition and rhythmatic contractions of the palate. I recall one case which I have seen who would have rhythmatic spastic contractions of the lower jaw. He would open his mouth as if to speak and then it would close.

In cervical spasms of function he gives cases of spastic torticallis, spasms of phonation and paraxysmal tachyphemia. The spasms of the thorax show a rather interesting group of cases. They may be grouped as disturbances of respiratory rhythm more commonly 
seen in children, paroxysmal polypnea which seems to be more common at nightfall, spasmotic cough and respiratory tics such as blowing, sniffing, spitting barking and laughing.

The spasms of function are peculiar in that they seem to effect bilateral muscles and have a synergistic muscle action. They eventuate in not a common tonic or clonic muscle spasm but correspond to a given function. They, he states, are often excited by emotion and ameliorated by repose and sleep. In looking over the case histories of some of the cases which present the oculogyric crises, the patients often state that with sleep the attack leaves them.

Rogers (61) also offers a theory as to its cause. He states, "The physiopathic basis of paralysis and spasm is thought to be a leison of irritation of the associated fibers between the nuclei of origin of the corresponding nerves. The rapid appearance and disappearance suggests a vasomotor disturbance."

Marion Brown and C. G. Imic (17) studied a case of bradynoea with a Parkinson syndrome by measuring the tidal air and the rate finding a tidal air of 1736 C.C. as against the normal of $500 \mathrm{c.c}$. and a rate of three to four per minute as against the normal of seventeen. They seem to regard it as a disturbance of the respiratory center, arising from pathological changes as a result of epidemic encephalitis. 
Probably the most common syndrome seen in this disease is the so-called Parkinson syndrome, the masked expression, general muscular rigidity, loss of well-known associated movements in walking like the swinging of the arms, the neck flexed on the shoulders, the arms flexed at the elbows and the flexion and adduction of the fingers, the pill rolling tremor, the oily sweaty skin, silarrhea and the propulsion gait w1ll make a fairly complete picture.

Hunter (40) in writing about it states, "The most common is Parkinsonism and second in importance is the mental changes and changes of character." Castro (19) states "The most important mental changes are those of character and emotion."

Probably the greatest occurrence of mental changes are found in children. Paterson (55) quotes Buzzard in saying, "I am convinced that a large number of cases of epilepsy, mental deficiency, hemiplegias and diaplegias are permanent results of attacks of epldemic encephalitis in children." Paterson (55) gives a series of twenty-five cases, their ages running from three months to eleven years. Of these, one died, six made a complete recovery, the other elghteen showed chronic signs; of the eighteen cases left, seven were mentally deficient grossly and unable to recognize their parents, they showed drooling, abnormal movements and idocy. The other eleven cases were only slightly deficient and show mostly psychical phenomen. 
Gibbs (32) in writing concerning the colony which has been established at King's Park to care for these chronic encephalitis children says, "The behavior disorder of epidemic encephalitis seems to have a fairly definite course in different phases, of different duration in different children, and apparently not determined by external influences."

The disorders commonly found in children who have had an acute attack and later go into the chronic stage might be listed as irritability, restlessness, purposeless impulsive acts, explosive breathing, changability of emotions, pucocity of sexuality, intense eroticism, flts of anger, cruelity to animals and people, destructiveness, kleptomania, mental retardation, criminal traits, and disturbances of sleep.

Bond and Partridge (14) in reviewing the works of wimmer list the following which he found to be the most prominent behavior disorders: restlessness, garrulousness, meddlesomeness, wide awake but erratic attention, curiosity, moods of foolish mirthfulness, irritability, queer manners, desire to tease, querulousness, marked emotional instability with outbursts of anger, destructiveness, biting nalls, auto-mutilations, willful spitting on others, violence firesetting, cruelty, vagrancy, begging, dishonesty, mendacaty, pilfering, shirking and precoclous eroticism.

Beverly and Sherman (9) list the following disorders which they found most frequently: 
inability to sleep at night, change of disposition, violent outbursts of temper, irresponsibility, incorrigibility in school, changes in school work, cruelty to animals, emotional shallowness, childish mannerisms, impulstve delinquencies, poor insight, appearance of deterioration, hyperactivity, irritability, alertness, marked emotional instability, explosive reactions, but also marked indifference and sluggish physical reactions.

This in itself presents a very grave problem. Here we see a child who was apparently normal in all respects, but following a touch of a "magic wand", so to speak, has been transferred into some sort of a demon for which society has no place. Schools could not take care of them, feebleminded institutions were not fitted for them because they were too intelligent, state hospitals could not take care of them because they were too young and it was not adequate, reformatories could not do good correction in this, and was useless. Colonies have been organized to take care of them. In these colonies they are kept busy from the time they arise in the morning until they go to bed at night; that is, all of their time is taken up by something useful throughout the entire day. For misdemeanors they were not severely punished and fairly good results have been accomplished with these children. Some have gone home on trial, and others fail to make a great lot of progress. Of those who have left these colonies, some have returned, and others have been able to adjust themselves to society. 
In quoting Bond and Partridge (14)--"So far no routine medical treatment has been found which promises much. Good hygiene, simplified life, with educative, expecially occupational programs, see, hitherto to have offered the most in the way of treatment." In all it practically looks like a problem of re-education. The question of the effect of pregnancy on acute and chronic epidemic encephalitis and the effect of the disease on the pregnancy has been the subject of much controversy. The second edition of the Matteson Commission (49) seem to take the view that the disease seems to have very little if any effect on the pregnancy, but pregnancy seems to effect the disease by increasing its rate of progress. Blard and Goldstein (10) in reviewing the literature and studying some cases of their own, arrive at the following conclusion; that women suffering from chronic epidemic encephalitis are not sterile; that incidence of abortion is about the same in patients suffering from chronic epidemic encephalttis and nonepidemic encephalitis is about the same; that pregnant women are not more susceptible to an acute infection of the disease than are non-gregnant women; that clinically the disease progresses about the same in both individuals but the mortality rates seems to be higher in the pregnant woman; that pregnancy may excite a latent form of epidemic encephalitis; that pregnant women who develop acute epidemic encephalitis are more prone to develop chronic epidemic encephalitis of the Parkinson syndrome; that chronic epidemic encephalitis does not effect the course of labor; 
that the pregnancy has a decided ill effect on the disease and that it is possible to transmit the disease from mother to fetus. With these conolusions it seems to show that while there is a definite and decided effect on the mother, there is very little effect on the pregnancy. In the Hatteson Report Second Edition (49) there are a few cases cited in which the newborn babe developed acute epidemic encephalitis or had it at the time of birth, but these cases are exceedingly rare and I think only three or four cases have been reported.

The prognosis of epidemic encephalitis varies somewhat as has been show previously in that there is no way of measuring or determining what patients with the acute infection will develop the chronic symptoms. At first, early in the epidemic, if a patient lost his acute symptoms his outlook was quite good if he did not at once develop chronic symptoms, but as years passed there has been a change of viewpoint and no one can predict what the outcome will be, time alone will tell. Some of those who are invalids now cannot give a history of ever having an acute attack, but do give a history of a slight upper respiratory infection which lasted a few days and about which they noticed nothing in particular, thus the attack being very mild. Others with severe symptoms go on to a complete recovery and seem apparently normal individuals years later. House (42) in a report of ninety acute cases found a mortality rate of twenty to thirty-three per cent with fifty-five to sixty per cent showing the chronic phase and $t$ en to twelve per cent showing complete recovery. 
Grossman's figures (34) in a series of ninety-two cases gives about a twenty per cent mortality with ten per cent recovery, and sixty to seventy per cent developing a chronic syndrome. Dunn and Heagey (22) in a report of one hundred cases, give a mortality rate of thirty per cent approximately, but do not give percentage of chronic cases. So, judging from the figures presented about five to seven out of every ten who develop the disease show some residual infection. The prognosis then, as to complete recovery, is rather poor. In any case it should always be guarded, as one cannot fortell either the course or consequence.

The diagnosis of epidemic encephalitis should be comparatively easy if one bears in mind that it is an acute infectious disease of the neverous system which can only be compared with syphilis and multiple sclerosis, neither of which are acute and febrile. Wechsler (67) in discussing the diagnosis says, "In general it may be said that any acute illness of the nervous system characterized by a mild degree of fever, by drowsiness or insomnia, by slight meningeal signs, especially a slight increase of lymphocytes in the spinal fluid, by scattered signs, such as pupillary signs, ocular palsies, radicular pains, myoclonic or other abnormal movements, and by masked facies, together with rigidities or loss of automatic and associated movements which protend a Parkinson syndrome, justifies on direct evidence a diagnosis of epidemic encephalitis." 
It is not, however, as easily diagnosed as stated, because of its wide range of symptoms, especially in an isolated case.

Several diagnostic symptom groups have been used as a means to an end in the diagnosis. K. Winsiow (70) in a discussion of the differential diagnosis gives a tetrad consisting of 1 . weakness, 2. fever, 3. lethargy, 4. and cranial nerve palsies, and with these present in the acute stage, he feels that a diagnosis of epidemic encephalitis is justifiable. Josephine Neal (51) gives a triad of symptoms used by the English and French, consisting of, 1. 1ethargy, 2. oculomotor palsies, 3. and asthemia which she states is probably in the time which these originated. It probably was all that was necessary since it was during the time of an epidemic, but if in the presence of an isolated case, I doubt if it would be possible, but at least it should present itself for the problems of differential diagnosis.

In looking over the problem of deferential diagnosis, epidemic encephalitis, since it simulates so many diseases of the nervous system draws a considerable number of diseases from which it must be differentiated in the acute stage.

Botulism, with which it was originally confused, is generally caused from eating food containing the toxin produced by the bacillus. It usually occurs in small outbreaks with a history of all those involved having eaten of the food, it is usually more acute and more rapidly fatal. 
Multiple sclerosis in the acute stage or in an acute exacerbation also enters the problem, the history of previous attacks, the finding of more pyramidal tract involvement that extraphyramidal tract, the fever, the pupillary anomalies and the chronic symptoms should point toward the diagnosis.

In cerebrospinal syphilis, the diagnosis would rest principally on the lack of fever in syphilis and the serological reaction. Tumors of the brain are also capable of producing a varied group of symptoms in this case the finding of a high cell count of the spinal fluid, presence of fever, and acute course should favor a diagnosis of epidemic encephalitis, since at times a choked disc is a finding common to both. Acute poliomilitis, especially if it involves the brain stem tends to show polymorphonuclear cells on spinal puncture, the eye muscles are not so frequentiy involved and there is a tendency for flaccid paralysis not seen in epidemic encephalitis.

The different meningeal irritations should offer no problex if spinal puncture is done and the fluid examined.

Typhoid fever may present the comatose conditions seen with this disease but should be ruled out by the physical signs of rose spots, continued fever, diarrhea and finally the widal reaction. Uremia and diabetic coma may also be present, a problem which could be easily solved by urine analysis and blood chemistry. Hysteria may often come into the picture and can be ruled out by absence of fever, history and nerve palsies. 
In proceeding to a diagnosis of the chronic condition, it is usually made from the history of an acute infection, plus the characteristic findings of muscular rigidities, tremors, masked facies, ocular palsies, and changes of character and emotion. Several triads of symptoms have been formulated by different oservers. Ornsteen (52) gives the following triad for its early recognition: 1. The finger posture or position, which is an increase of the flexed position of the fingers at the interphalangeal segments, with or without the same change at the metacarpel-phalangeal segments as well as closer approximation of the thumb and forefinger. 2. Assymetry of the spacing of the fingers of the outstretched hand with less separation of the fingers and abduction of the outstretched thumb from the hand affected. This is the finger spacing test. 3. The thumb forefinger test, which consists of touching the thumb and forefinger rapidly together, the affected side does not describe such a large arc of motion and exhaustion is more rapid.

Hadden (35) describes another triad of symptoms which he says are present in the chronic case and where if present Parkinsonism will develop later. 1. Rapid blinking of the eyes, the rhythm and amplitude quickly become irregular and eventually the lids become fixed and there is a rapid fluttering. 2. The tongue is placed up behind the upper incisors and snapped rapidly in and out of the mouth, soon the rhythm becomes irregular and the tongue finally fixed. 
3. With the teeth firmly together the patients rapidly smack Iips loudly. Soon the smacking is inaudible and the movements irregular. He states that after observing a few normal, a person soon learns to pick up the potential Parkinsonian.

The chronic stage must be differentiated from the true Parkinson's Disease or Paralysis Agitaus. Paralysis Agitaus appears later in life or in older persons, the tremor is the typical pill rolling tremor which may be present in the epidemic encephalitis case but is usually not quite so typical. General muscular rigidity may be present in both but the "cogwheel" phenomenon is not usually seen in the Paralysis Agitaus. The gait may be the same with some tendency to be more accentuated in the Parkinsonian. Usually in Parkinson's Disease there is not so much involvement of the muscles of the head and neck as in the chronic epidemic encephalitis, and as a rule, the tremor and rigidity develop more rapidly in the encephalitis. The symptoms of vegetative nervous system involvement are also met with in both cases, but more commonly in the epidemic encephalitis. However, in cases in which the skin is very greasy, drooling quite pronoinced, and the secretions of the lacrimal glad causing epiphoria a diagnosis of chronic epidemic encephalitis can probably safely be made. Symptoms of the corpus striatum involvement in the form of the hyperkinitio phenomen with repetition of automatic movements such as smacking of the lips, snout cramps and the like favor a diagnosis of epidemic encephalitis. 
Certain positions assumed in which the patient keeps for hours must be differentiated from schizophrenia and hysterical reactions. These must be ruled out by history and signs of organic pathology.

Multiple scherosis has been mentioned and should be thought of again, but history of the remissions, typical speech, nystagmus more often found in multiple scherosis and pyramidal tract involvement with bitemporal palor of the optic disc shoudl serve for differentiation.

Brain tumor, cerebrospinal lues and pychroneurosis may also enter into the picture, but should be differentiated by the previous discussion, which the pychoneurosis would have to be differentiated by history and physical and neurological findings.

When one finds a great multitude of treatments for any disease the most logical conclusion is that none of them are of any or very little value. By way of a general statement, it is purely symptomatic. Probably a great share of the drugs in the pharmacopeia have been used without results. The reports of the Matheson Commission have reviewed quite well the drugs used and usually end their discussion by stating there is not sufficient evidence.

I will discuss a few of the recent drugs which have come into the literature and give the conclusions of the writers.

Hill, Worster and Drough (38) in discussing harmine in chronic epidemic encephalitis finally arrive at the following conclusions: that harmine given by "hypo" up to $.04 \mathrm{gm}$ has no objective or subjective signs on chronic epidenic encephalitis; 
that it produced nausea and vomiting probably as a result of central action; that in one case of thirty-eight, tachyponea was partially relieved.

Salicylates have been used in large doses, but seem to have no appreciable effect. Epstein, Farnham and Bobb (24) state that it has been used by the French who claimed good results, but their conclusions after some study were, that there is no evidence that it helps materially in the chronic stage, but there is some evidence that salicylates help in the acute stage when given in large doses.

The vaccine developed by Roseneau in being tried by the United States Vetraus Bureau, according to results obtained by Epstein and Foote (25) in six cases is of very little value.

Gucose therapy has been the recomended, and given both orally and introvenously in large doses, but seems to have very little therapeutic value, but if any it is in the acute stage. Alford (2) by way of a summary of this study of glucose states "In general, results are best in the more acute cases and least favorable in Parkinson and other syndromes where actual destruction of tissue can be assumed to have occurred."

Von Economo used Pregols solution ( $10 \%$ sodium iodide) 100 c.c. intravenously for ten to fifteen weeks once each week, but apparently failed to get any definite results. He also used thirty to fifty c.c. of $2 \frac{1}{2} \%$ sodium salicylate intravenously twice daily for ten days but with the same results. 
Acroflavine has been used, urotropin, non-specific protein therapy, malaria, adrenalin, methylene blue, arsenic, bismuth, calclum, gelsemium, physiotherapy, quinine, strychnine, sulfur, trypan blue and many other drugs of minor importance, but after a trial, the evidence that they are of any value is still wanting.

A few drugs of the belladonna family have been found to be of value as symptomatic measure. Of the belladonna family scopolomine, atropine, stromonium and hyosine have been tried. Hyosine and stromonium have been found to be the most valuable. There seems to be some question as to which of the two is the better. Burns (18) states that stromonium not only lessens the muscular rigidity but also has an effect in relieving mente.l symptoms also which hyoscine does not have. Other observers have used both drugs and have found them to be better and in their hands have produced more nearly the desired effect.

Stromonium can be given as the extract or much better as a tincture. It is usually started at a small dosage of fifteen to twenty drops three times a day and increased three drops daily until toxic symptoms appear, then reduced slightly and kept at this. One patient whom I saw in the out patient department was taking one dram per day.

Hyoscine is best administered in the salt hyoscine hydrobromide tablets of $1 / 100$ to $1 / 150$ of a grain each day, and patients derive the desired effect.

Scopolamine and atropine have been used extensively, but their effect does not seem to be so well regulated and their other reactions are not quite those desired. 
These drugs act only by making the patient more comfortable by lessening the muscular rigidities tremors and secretions. I recall one patient whom I saw, who at the time he entered the hospital was unable to feed himself or take any care whatever of himself. After a few days of hyosine therapy this patient was feeding himself as well as dressing himself. The drooling had been reduced until it was hardly noticeable.

Convalecent serum was recommended as treatment in the acute cases, but the Matheson Report regards it as not yet having been proven.

Beckman (7) in his text book of therapy states that in the acute stage, ample diet, forcing fluids, keeping the body clean and protecting the body from external sensory stimuli is about all that can be done. Some writers have also advised forcing of fluids but with the use of spinal drainage in addition. In conclusion we will have only to repeat our opening statement that treatment is only symptomatic.

The problem of this disease, of unknown etiology, definite pathology, with multiple and wide-spread chains of symptoms, a very definite morbidity and treatment which is as yet quite unsatisfactory is still as yet unanswered, and as Von Economo has said, until more is known of the causative agent very little can be done to prevent it and the therapeutic phase will still be experimental and symptomatic. One can see that should it become again the creeping monster which leaves after it a trail of mutilated nervous systems, we would still be with our hands bound and practically as helpless as we were in 1918. 


$$
-35-
$$

I am presenting, along with this paper, case histories of six patients which I have studied to some extent. I present them because they each present a different symptom complex. Case I presents the oculogyeric crises. Case II presents a typical Parkinson syndrome with auditory halluncinations. Case III is a typical Parkinson syndrome. Case IV, in my estimation presents, along with a Parkinson syndrome, a behavior disorder, or mental deterioration. Cases $V$ and VI, present chronic epidemic encephalitis with psychosis. 
Case I

A $M$

white, German-American, female, single, age 18, school

student, entered the State Hospital for the first time December 31, 1929 complaining crying spells, fit of anger, blurring of vision, and slowness of movements.

Present IIIness:

Present illness began several years ago in 1921; patient had a mastoidectomy. One year following she had an attack of "flu" with blurring of vision, headache and diplopia, following which she would have crying spells, nightmares, headaches and seemed to be afraid of everything. She had no treatment until 1924 when she was treated by a lady who hypnotized her, but she received no relief. Following that she received treatment from a chiropracter. She was then taken to the Mayo Clinic who sent her home but without any assurance and gave her some medicine. Patient continued in her previous condition until late in 1928 when she developed weakness of her muscles and tremors developed in both upper and lower extremities and stiffness of her muscles. States also that she has trouble with her eyes in that they turn back in her head which causes her to become very angry and fight someone who is near her. Says these attacks come every three or four days and last one to two hours. Past History:

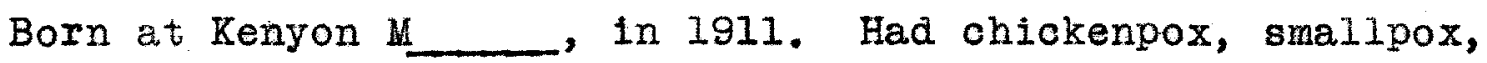
measles, without any serious sequelae and went to the seventh grade in school at which time she developed her present iliness. 
Pamily History:

Father living and well, age 45. Mother living and well, age 42. Four brothers and one sister. Family history negative for insanity, tuberculosis, diabetes and cancer.

Personal History and history by systems is irrelevant.

Physical examination and neurological examination:

Nutrition good, eyes react to light and accommodation, slight ptosis of left eye Iid, and slight nystagmus to left, Tremors were present of tongue, arms, and face. Face was oily and expressionless knee perks were hyperactive. The patient had the typical Parkinson attitude in walking, would also show retropulsion. Other reflexes and physical findings were negative, speech slow and difficult. Laboratory Findings:

Negative spinal fluid cell count 1 ;

Protein 24 Wasserman negative, Colloidal Gold 000000000

\section{Progress :}

Patient put on tincture of stromonium MX XL once each day and $1 / 150 \mathrm{gr}$. of hyoscine hydrobromide. Patient is very helpful when not having an attack and if the attack does not come too rapialy she asks to be put in restraints so as not to hurt anyone. Attacks come however, about every three to four days during which she becomes quite violent and unmanageable, using much profane language. Attacks usually last three to four hours after which she is quite restless for another three or four hours. 
Case II

$\mathbf{S}$

D White, German-American, single, male, age 19, ordinary

laborer, committed to the State Hospital for the first time Hay

$21,1926$.

Present IIlness:

Patient suffered an attack of influenzia in 1919, was in bed for two weeks which was followed by "sleeping sickness." The first symptoms noticed were blurring of vision and double vision. He would also have spells of swaying like a pendulum from side to side. About two years later he started acting queerly and was subjected to attacks of uncontrollable anger, throwing things about the house. During one of these attacks he struck his grandmother with a stove poker, injuring her quite severely. Parents state that he did not seem to act natural but just like a child. He would repeat words which meant nothing at all but could not tell why he said them. Later stated that he heard voices speaking to him and it was they which told him to strike his grandmother and to destroy things. Has had a tendency to be by himself and not associate with other children. Patient states that this was because he was not wanted for he was so quick tempered and had so many fights.

Past History:

Born at St. P_H. In 1904, had the usual childhood diseases and has always been healthy. Finished four years of high school, and has worked as a lumber cutter but did not like it, so he quit and had been unable to hold a job since then. Family History:

Father age 69, living and well, Mother age 65, Iiving and well. 
Four brothers and two sisters living and well. None dead. Laboratory Findings:

Weight 191 pounds. Nutrition good. Patient assums the typical Parkinson posture, the face is expressionless and dull, there is a slight drooling of the mouth, the right arm is flexed at the elbow and patient shows coarse tremor of both hands more marked and assuming the pill-rolling tremor of the left. There also is tremor of the tongue and facial muscles about the mouth, Ptosis of the right eye, pupil react to light and accommodation. There is an incoordination of movements of the left hand and arm. Movements are all deliberate and slow. Deep reflexes are all hyperactive. Abdonimal and epigastric reflexes are absent but the cremasteris is present on both sides.

Progress:

Patient at present is on hypscine hydrobromide grs 1/100 once each day and he says it makes him feel very much better. He does, however, have occasional difficulties with the other patients after getting into fights with them. Does not do any work except plcking papers off the lawn which he attends to diligently. 
Case III

$\mathrm{P}$ F White, American, single, male, age 31, farmer, entered the State Hospital for the second time, complaining of increasing tremor of his left hand and slowness of movements. Present Illness:

In the spring of 1920 patient had influenzia following which he slept for about two months following which he has some paralysis of his right arm and face. About one year later he noticed his left arm began trembling and he was very nervous. His speech became difficult and has been getting gradually worse. Patient also notices that he drags his left foot some in walking, and that his mouth is always full of saliva.

Patient was in the hospital five years ago for treatments, was given eighteen intravenous injections of $50 \mathrm{c.c}$. of $10 \%$ sodium iodide which did not seem to help him very much. He was put on hyoscine hydrobromide grs. 1/100 daily and discharged. Thinks he is getting quite a bit worse and came in this time voluntarily to see if he could get some other medicine. Personal History:

Born at $M$ M__ in 1900, has had no childhood diseases except "flu" in 1930. Operated on for appendicitis twelve years ago. Has had gonorrhea but denies syphilis. Finished the eighth grade in school. Has had no trouble getting along with people or holding jobs.

Family History:

Father dead, age 67, gall bladder disease. Mother Iiving and we1l. Has five brothers and one sister living and well, one cousin insane, family history otherwise negative. 
History by systems practically negative.

Physical and Neurological Examinations:

Nutrition good, weight 119 pounds, expression masked, ptosis of right eye and sapstic paralysis of right side of the face, speech slow and difficult, heart chest and abdomen are essentially normal, marked tremor of tongue, eyelids, hands and arms, some atrophy of muscles of the fore arm of left side, grasp of left hand weaker than the right, some atrophy of muscles of left leg and thigh, gait is spastic with dragging of left leg, has marked drooling of saliva and face seems quite oily, hearing on right side impaired. Reflexes: Babinski and Hoffman present on left side, otherwise practically all others are normal to increased. Has coursepill-rolling tremor of left hand. Typical Parkinson station. Laboratory Findings:

Urine negative, blood and spinal Wasserman negative, collotdal gold 000000000

\section{Progress:}

Patient only stayed for a few days. He was started on tincture of stromonium was started but patient left before tolerance and therapeutic effects were obtained. 
Case IV

C B White, American, male, single, age 26, entered the hospital for the second time August 18, 1932, being committed on charges of stealing, window peeping, and bestiality.

Present IIlness:

In 1924, patient states, he had quinzy, sore throat, which was lanced three times. Shortly after this he developed "sleeping sickness" and was in bed from December, 1924 until April 1925. During this time he slept thirteen consecutive days and nights. Since then he has had trouble speaking plainly, has always felt tired, moved very slowly, and saliva drooled from his mouth. Patient was brought into the hospital the first time because he had been caught stealing money from a filling station and was a general nuisance around town. Patient denies window peeping and bestiality of present complaint, but states that he did break into a filling station and steal money, and that he had "beaten up" an old man who ran a pool room because the man hit him when he attempted to get a glass of water.

Past History:

Born L___ in 1906, gives a history of measles, typhoid fever, and influenza in 1918. No injuries or accidents. Finished the eighth grade in school, which took him ten years. History by systems negative.

Family History:

Father 11ving and well, age 69. Mother dead, age 48, typhoid pneumonia. Has four brothers and five sisters all Iiving and well. Family history is negative otherwise. 


\section{Laboratory:}

Blood; cell count and wasserman negative

Spinal fluid; cells 4, protein 12 mgm., Wasserman negative Urine; negative

Physical Examination and Neurological Examination:

Welght 143 pounds, well developed, well nourished male of about twenty-five years. Face is somewhat "ironed out" and quite oily, has an excess of saliva which occasionally drools out. Mouth is open constantly and tongue protrudes slightly. Pupils react to light and accomnodation, and speech is somewhat slurred. Patient in walking assumes the Parkinson attitude. Slight tremor of hands and tongue is present. The left hand grasp seems stronger than the right. Refiexes and cranial nerves seem apparently normal. Mentally, patient seems alert and perhaps a little retarded. Progress:

Patient seems to have very little difficulty while in the hospital. Does show tendencies to be somewhat childish. Helps around the wards and wants to cooperate with all. The first time the patient was in the hospital he was given liberty of the grounds but had tendencies to wander away and on one of these wanderings he never came back until returned by the sheriff at the present time. Was put on hyoscine hydrobromide grs. 1/150 daily which relieved his spasticity somewhat and tended to reduce the secretion of saliva. 
Case V

I_____ White, American, male, divorced, salesman, age 26, committed to the State Hospital, August 26, 1927, because of irritableness, nervousness, extremely bad temper and $f i t s$ of temper without cause, fancied troubles with other people, and that they were plotting against him.

Present I11ness:

Patient was sent to the State Hospital from the State Penitentiary and placed in the Criminal ward. He was charged with assult with intent to comitt felony. Sald assult being attempt to committ rape. He was given an indeterminent sentence.

Patient states that in 1923 that he was on the bettleship Wyoming as a sailor, that some oil caught fire in the hole and in combatting this fire he was gassed and taken to a government hospital where he remained for 9 months and during this time he had "sleeping sickness". After this he was discharged from the Navy. Following his discharge he had several times gotten into trouble because of his "temper", which he states was not present before his entrance to the hospital.

The incident which brought him into the hands of the court he states was when a woman attempted to make love to him while he was trying to sell her some magazines. When he tried to make love back to her she resisted him which made him very angry and during the scuffle which followed he broke her nose.

While working in the penitentiary he states the guards "beat him up" because he would not obey orders. Following which he developed a tremor of his left leg and also of his right leg and arm, patient does not think this is the result of the beating but from 
running a sewing machine. Since then he has also developed some tremor of his left arm. This he states came on in 1926.

Past History:

Born at B___ in 1901, has had usual childhood diseases without any sequelae, finished the 8 th grade in school and always got along well in school. Gained the Navy in 1921.

Family History:

Essentially negative. No family history of insanity. Physical and Neurological Examination.

Nutrition good, weight 149 pounds, teeth in good condition, eyes react to light and accomodation tongue shows some tremor, face is "ironed out" and shows excessive oiliness of the skin, heart, chest, and abdomen essentially negative, tendon reflexes are hyperactive, has a positive Hoffman on the right side, and also a Bobinski on that side, shows irregular tremor of both hands and feet more marked on the right side, muscles are quite spastic, has loss of associated movements on walking but does not show any silorrhea. Laboratory Findings:

Blood and spinal Wasserman's negative Colloldal Gold Negative

Urine negative

Spinal cell count 3

\section{Progress:}

Patient was put on hyoscine hydrobromide grs. 1/150 daily, but refused to take it after one week because of dryness of his mouth. Tincture of stromonium was tried but patient also refused to take it because he thought it did him no good and that we were just 
forcing this on him, so this was discontinued. His tremor has not increased nor has any of his other symptoms. He has trouble occasionally with the rest of the patients but is essentially in the same condition as on entrance. 
Case VI

A_A_ White, Norweigan, male, single, age 40, laborer, entered the State Hospital for the first time Novernber 30, 1929 complaining of people trying to $\mathrm{kill} \mathrm{him}$.

\section{Present IIIness:}

Upset commenced several weeks ago and has gradually been becoming more pronounced. Has been a farm hand all his life. States that five years ago he had an attack of "flu" and was in bed for about 8 weeks, during which time he had very severe headaches diplopia, slept all day and could not sleep at night. States that about fours years ago he began to notice that his muscles were getting stiff and that he tired more easily than he did previously, which has been getting progressively worse. He was unabie to do his work so was taken to the poor farm but did not like it there and thought some of the inmates were going to electrocute him so he ran away and was found by the sheriff who brought him here.

Pact History:

Essentially negative. Born in Norway. Family History:

His parents and relatives are all in Norway and he does not know as to their health and condition. Physical and neulological Examination.

Patient is rather undernourished, shows a masked expression, walks with a slow somewhat spastlc gait, movements are all slow, has $10 s$ of assoclated movements on walking. Physically the patient shows no defects or abnormalities except a scar on the abdomen apparently an operative scar, tongue shovs some tremor and 
also the hands, tendon reflexes are hyperactive, otherwise neurological examination is negative.

Laboratory findings:

Blood cell counts negative, Wasserman negative

Special fluid, cell count 11, protein $24 \mathrm{mgm}$.

Wasserman negative, colloidal gold negative.

Urine essentially negative.

\section{Progress:}

Patient is very cooperative has been taking hyoscine hydrobromide grs. I/150 daily and states that it makes him feel much better. Patient was given 18 introvenous treatments of 50 c.c. of $10 \%$ sodium iodide two treatments each week during which time he gained 21 pounds but his symptoms were in no way relieved. For past few months patient has been having some trouble passing his urine and occassionly has to be catherized, no enlargement of his prostate has been found or any other finding to explain this. Patient has however lost practically all of his delusions, and gets along quite well with the other patients. 


\section{BIBLIOGRAPHY}

1. Abrahamson, Q., Chronicity in Lethargic Encephalitis, Archives of Neurology and Psychlatry, Vol. 4, P. 428, 1920.

2. Alford, L. B., Glucose Therapy in Epldemic Encephalitis, Southern Medical Journal, Vol. 21, P. 649, 1928.

3. Barker F. L., Diagnosis and Treatment of Parkinson Like Syndromes of Chronic Epidemic Encephalitis, Medical Clinics of North America, Vol. 14, P. 131, 1930.

4. Barr, C. H., Sequelae of Epidemic Encephalitis without any Preceeding Acute Attack, Archives of Neurology and Psychiatry, Vol 14, P. 20, 1925.

5. Bassoe, Peter, Epidemic Encephalitis, Journal of the American Medical Association, Vol. 72, P. 971, 1919.

6. Beal, K. H., Lethargic Encephalitis, Texas State Medical Journal, Vol.15, P. 129, 1919.

7. Beckman, Treatment In General Practice, pp. 670-671.

8. Bennett, A. E., and Patton, J. M., Oculogyric Crises in Postencephalitis Syndromes, Archives of Ophthalomology, Vol. 4, P. $361,1930$.

9. Beverly and Sherman, Post-encephalitis Disorders of Behavior, without Pysical Signs, American Journal of Diseases of Children, Vo1. 27, P. 565, 1924.

10. Blard, P. B. and Goldstein, L., Pregnancy with Parkinsonism, Journal of the American Medical Association Vol. 95, P. 473, 1930.

11. Blackstone, H. A., Post-encephalitis Parkinsonism, Senior Thesis.

12. Bond, E. D., Behavior in Children, Journal of Indiana Medical Association, Vo1. 23, pp. 205-208, 1930.

13. Bond and Appel, Treatment of Post-encephalitis in Children, American Journal of Psychiatry, Vo1. 10, P. 815, 1931.

14. Bond and Partridge, Post-encephalitis in Children, American Journal of Psychlatry, Vol. 6, P. 3, 1926.

15. Boyd, W., Pathology of Internal Disease, pp. 731-745.

16. Boyd, W., Epidemic Encephalitis, Study of 75 Cases with 16 Autopsies, Annals of Medicine, Vol. 1, P. 195, 1920.

17. Brown, Maude and Imrie, C. G., Persistant Bradynoea in a case of Parkinsonism, Quarterly Journal of Medicine,Vol, 1, P. 319, 1930 . 
18. Burns, M. M., Use of Stromonium in Treatment of Encephalitis Lethargica, Psychiatric Quarterly, April, 1931.

19. Castro, Herman, Sodiun Iodide Therapy of Post-encephal1tis Psychosis, Archives of Neurology and Psychiatry, Vol. P. 1927.

20. Compton, H. L., Oculogyric Crises in Chronic Epidemic Encephalitis, United States Veteran's Bureau Medical Bulletin, Vol. 7 , P. 1150, 1931 .

21. Courtney, J. W., Concerning So-Called Encephalitis Lethargica with Special Reference to Its So-Called Sequelae, Boston Medical and Surgical Journal, Vol 183, P. 123, 1920.

22. Dunn, A. D. and Heagey, F. W., Epidemic Encephalitis Review of 100 American Cases, American Journal of Medical Sciences, Vol. 160 P. 568, 1920 .

23. Evans and Freeman, Studies on Epidemic Encephalitis, United States Public Health Report, Vol. 14, P. 1095, 1926.

24. Epstein, S. H., Farnham, R. H., and Cobb, S., Use of Salicylates in Treatment of Chronic Epidemic Encephalitis, Boston Medical and Surgical Journal, Vol. 197, P. 1552, 1928.

25. Epstein, J. \& Foote, E., Epidemic Encephalitis, Lethargic, Treatment, United States Veteran's Bulletin of Medicine, Vol. 7, P. 864, 1931 .

26. Fisher, G. S., Stromonium in Chronic Epidemic Encephalitis, United States'Veteran's Bureau Medical Bulletin, Vol. 7, P. 864, 1931.

27. Fisher, G. S., Epidemic Encephalitis, United States Veteran's Bulletin of Medicine, Vol. 7, P. 379, 1931.

28. Flexner, Simon, Lethargic Encephalitis, History, Pathology and Clinical Features in brief, Journal of the American Medical Association, Vol. 74, P. 865, 1920.

29. Francais and Lancon, Remote Sequelae, Archives of Neurology and Psychiatry, Vol. 17, P. 836, 1927.

30. Freeman, W., Epidemic Encephalitis, Journal of the American Medical Association, Vol. 87, P. 1601, 1926.

31. Freeman, w., Specific and Non-specific Remedies in Treatment, Journal of the American Medical Association, Vol. 89, P. 864, 1931.

32. Gibbs, C. E., Behavior Disorders in Chronic Epidemic Encephalitis, American Journal of Psychiatry, Vol. 9, P. 616, 1930.

33. Greenfield, J. G., Epidemic Encephalitis, Morbid Anatomy of, British Medical Journal, Vol. 2, P. $782,1920$. 
34. Grossman, M., Sequelae of Epidemic Encephalitis, Journal of the American Medical Association, Vol. 78, P. 959, 1922.

35. Hadden, S. B., Insipient Parkinsonism, A Gropp of Objective Symotoms, Archives of Neurology and Psychiatry, Vol. 26, P. 392, 1931.

36. Henderson and Gillispie, Text-Book of Psychiatry, 3rd Edition, PP. 326-335.

37. Hill, T. R., Post-encephalitis Parkinsonism as a Chronic Infection, Journal of Neurology and Psychopathology, Vol. 9 , P. 337, 1929 .

38. Hill, T. R., and Worster-Drough, Harmine in Treatment of Chronic Epidemic Encephalitis, Laucet, Vol. 2, P. 647, 1929.

39. Hohman, L. B., Histopathology of Post-encephalitis Syndrome, Bulletin John Hopkins Hospital, Vol. 36, P. 403, 1925.

40. Hunter, Charles, Late Sequelae of Encephalitis Lethargica and of Infiuenzia, Canada Medial Assoctation Journal, Vol. 24, P. 828,1930 .

41. Hope, C. W., Differential Diagnosis of Epidemic Encephalitis in Nigera, British Medical Journal, Vol. 2, P. 1001, 1930.

42. House, W, Sequelae of Epidemic Encephalitis, Journal of the American Medical Association, Vol. 79, P. 211, 1922.

43. Jay, F. P., and Holden, M., Herpes Encephalitis Problem, Journal of infectious Diseases, Vol. 45, P. 415, 1929.

44. Jelliffe, S. E., Psychologic Cornonents in Post-encephalitis Oculogyric Crises, Archives of Neurology and Psychiatry, Vol. 21, P. 491 , 1929.

45. Krabbe, K. H., Chronic Epldemic Encephalitis, International Clinics, Vol. 1, P. 100, 1928.

46. Leiner, J. H., Chronic Residual Infection Simultating Paralysis Agitaus in a Boy of Sixteen Years, Medical Record, Vol. 98, P. $1020,1920$.

47. MacCallum, Text-Book of Pathology, PP. 659-661.

48. Matheson Commission, Epidemic Encephalitis, First Report.

49. Matheson Commission, Epidemic Encephalitis, Second Report.

50. Miller, N. Richard, Treatment of Post-encephalitis, Senior Thesis.

51. Neal, Josephine, Lethargic Encephalitis, Archives of Neurology and Psychiatry, Vol. 2, P. 271, 1919. 
52. Ormsteen, A. M., Insipient Parkinsonism a Diagnostic Triad, Journal of Nervous and Mental Diseases, Vo1. 75, P. 193, 1932.

53. Parker, H. L., Epidemic Encephal1tis Respiratory Syndrome, Medicine Clinics of North America, Vol. 13, P. 1347, 1930.

54. Parker, H. L., Respiratory Syndrome of Epidemic Encephalitis Medicine Clinics of North America, Vol. 13, P. 1347, 1930.

55. Paterson, D. \& Spencer, J. C. Laucet, Epidemic Encephalitis After Effects in Children, Vol. 2, P. 491, 1921.

56. Patton, J. M., Ocular Manifestations In Epidemic Encephalitis, Nebraska Medical Journal, Vol. 4, P. 265, 1919.

57. Perkins, J. N., Epidemic Encephal1tis, Chronicity, United States Veteran's Bulletin of Medicine, Vol. 7, P. 858, 1931.

58. Pothier, 0. L., Lethargic Encephalitis, Journal of the American Medical Association, Vol. 72, P. 715, 1919.

59. Rice, G. E., Epidemic Encephalitis, Late Manifestations and Atypical Forms, Journal of Iowa Medical Society, Vol. 16, P. 395, 1926.

60. Riley, H. A., Epidemic Encephalitis, Archives of Neurology and Psychiatry, Vol. 24, P. 574, 1930.

61. Rogers, Henri, Spasms of Function in Epidemic Encephalitis, Archive of Neurology and Psychiatry, Vol. 9, P. 697, 1931.

63. Steen, R. H. \& P., Chronic Epidemic Encephalitis, Cerebrospinal Fluid Study, Psychiatric Quarterly, Vol. 5, P. 90, 1931.

62. Schaller, W. F. and Oliver, J., Chronic Epidemic Encephalitis, Archives of Neurology and Psychiatry, Vol. 8, P. 1, 1922.

64. Thompson, B. A., Use of Hyoscine in Parkinson Residuals, United States Veteran's Bureau Medical Bulletin, Vol. 6, P. 709, 1930 .

65. Frederick Tilney \& Herbert $\mathbf{s}$. Howe, Epldemio Encephalitis.

66. Von Economo, Encephalitis Lethargica and Encephalomyelite Surgargne Diffusa, Journal of the American Medical Association, Vo1. 92, P. 1702, 1929.

67. Wechsler, Text-Book of Clinical Neurology, PP. 387-399.

68. Whittington, T. H., Ocular Complications of Chronic Epidemic Encephalitis, British Medical Journal, Vol. 2, P. 891, 1931. 
69. Wilson, K., Laucet, Epldemic Encephalitis, Vol. 2, P. 7, 1918.

70. Winslow, K., Differential Diagnosis in Epidemic Lethargic Encphalitis, Northwest Hedicine, Vol. 19, P. 73, 1920.

71. Wright, J., Epidemic Encephalitis, History, Medical Journal and Record, VoI. 126, P. 375-377; 569-571; 743-746; 1927. 